DOI: $10.12731 / 2070-7568-2017-3-147-163$

УДК 330.34

\title{
ПОВЕДЕНЧЕСКИЕ ФАКТОРЫ ПРОВЕДЕНИЯ ТЕХНОЛОГИЧЕСКОЙ МОДЕРНИЗАЦИИ В ЭКОНОМИКЕ РОССИИ
}

\author{
Яковлева Е.Л., Селиверстова Н.С., \\ Григорьева О.В.
}

Аналитические подходы к проведению технологической модернизации зависят от условий, которые те или иные исследователи принимают за базовые (индустриальный, институцииональный подходы). В статье рассматриваются факторы, учет которых необходим для успеха проектов по внедрению технологических новшеств (информационные систем и т.n.) на организациях различной направленности в экономике России (госучреждения, организации финансового и реального секторов экономики).

Цель: определение поведенческих факторов, которые необходимо учитывать при проведении технологической модернизации в экономике России.

Метод или методология проведения работы: в статье использовались логико-исторические методы, а также общенаучные методы анализа.

Результаты: выделены некоторые наиболее информативные факторы, которые оказывают влияние на реализацию прочессов по внедрению технологических новществ в экономике России.

Область применения результатов: полученные результаты целесообразно применять экономическими субъектами, осуществляющими или планирующими технологические изменения.

Ключевые слова: электронное кочевничество; макроэкономика; информационные технологии; технологическая модернизация; поведенческие факторы; поведенческая экономическая теория. 


\section{BEHAVIORAL FACTORS OF TECHNOLOGICAL MODERNIZATION IN THE RUSSIAN ECONOMY}

\section{Iakovleva E.L., Seliverstova N.S., Grigoreva O.V.}

Analytical approaches to technological modernization depend on the conditions of that certain scholars take like a basis (industrial, institutional approaches). The article discusses about the factors which are necessary for the success of projects to introduce technological innovations (information systems, etc.) in the various kinds of organizations (in government, financial and real sectors of the economy).

Purpose: definition of the behavioral factors to consider when carrying out technological modernization in the Russian economy

Methodology: in article logical-historical methods, and also general scientific methods of the analysis were used.

Results: highlights some of the most informative factors that influence the implementation of technological innovations in the Russian economy.

Practical implications: results should apply by economic agents who engaged in or planning to implement of technological changes.

Keywords: electronic nomadism; macroeconomics; information technology; technological modernization; behavioral factors; behavioral economic theory.

\section{Введение}

Современное общество трудно представить без цифровых средств коммуникации: они прочно вошли и укрепились в бытии. Высокие технологии (hi-tech) и «информационный взрыв» (М. Маклюэн [18]) изменили и трансформировали социокультурное пространство. Электронный мир в своем цифровом и аналоговом воплощении есть постоянно расширяющаяся техническая инфраструктура (в том числе, сеть, беспроводные технологии, виртуальная реальность, спутниковое и цифровое телевидение, видео, Интернет, CD-Romы, электронная почта, мобильные медиа, навигаторы и пр.). Перечисленная техника постоянно комбинируется и гибридизируется, практически ежедневно обновляясь и захватывая все большее пространство. Бла- 
годаря ей появляются новые виды децентрализованного и удаленного производства и взаимодействия. За последние несколько десятилетий в мире накоплен довольно большой опыт по использованию информационных технологий. Современный человек не представляет своей жизни без определенного набора технических устройств, связанных с развитием высоких технологий [7]. Неслучайно ученые, в частности Алексеева И.Ю., Аршинов В.В., Чеклецов В.В., используют в научном обороте такие понятия как «техночеловек» [1], «техногенный человек», а поколение next все чаще называют метафорически - «поколением опущенных голов» (head down generation).

Вопросы, связанные с изучением поведенческих аспектов при внедрении и использовании информационных технологий и других аспектов технологической модернизации современных предприятий и организаций, представляют интерес для исследователей в различных направлениях научной мысли. Ведь новые технологии, облачные вычисления и т.п. изменяют существующие бизнес-модели, ставят новые вызовы перед экономическими агентами, создают новые риски и возможности для управления (менеджмента) и производства.

В то же время, внедрение информационных систем и их последующее использование, а также любой иной тип технологической модернизации, требует перестройки существовавших ранее бизнеспроцессов, изменение мышления персонала и перераспределение ролей внутри компании и в её взаимосвязях с внешними экономическими агентами, что вызывает трудности и многочисленные вопросы. Поведенческие аспекты при внедрении и использовании результатов технологической модернизации в современной экономике России изучены слабо. В частности, по данным компании Standish Group, только в 16\% случаев внедрение информационных систем завершается вовремя, в рамках запланированного бюджета, с реализацией запланированной функциональности [13]. Выполнение почти трети проектов досрочно прекращается, а по остальным превышаются сроки/ бюджет или ограничивается запланированная функциональность.

Особенности внедрения технологических новшеств российскими вузами, государственными учреждениями и организациями, компаниями реального и финансового сектора экономики не си- 
стематизированы, что создает поле для научных изысканий. В то же время своевременность необходимых организационных и технологических изменений является залогом успешного функционирования экономических агентов в современных быстро изменяющихся условиях хозяйственной практики.

\section{Основные результаты}

Прежде, чем проанализировать конкретные примеры современных техноинноваций, обратим внимание на поведенческие матрицы личности, очарованной высокими технологиями и техноновинками, прочно вошедшими в ее жизнь. Дело в том, что в современности происходит диалектический процесс, в котором не только человек производит технологии, но и технологии оказывают интенсивное воздействие на него [25; 8]. Пытаясь определить современную идентичность индивида, мы обращаем внимание на такой ее модус как электронное кочевничество. Идеи кочевничества как вида идентичности не новы: их интуиции содержаться в «Философических письмах» П.Я. Чаадаева, а термин «электронный кочевник» ввел в 2003 году У. Митчелл в исследовании «Я++: Человек, город, сети» [19].

Осуществим дескрипцию электронного кочевника, что поможет выявить современные поведенческие алгоритмы и риски, связанные с ними. Кочевник как страстная натура желает расширить собственные пространства бытия и ищет приключений. Кочевник - странник, находящийся постоянно в пути: он бродит по мирозданию, не имея дома и корней в бытии. Последнее качество высвечивает кризисность его жизни. Безусловно, свобода, связанная с чувством бездомности, первоначально окрыляет личность, но со временем - начинает подавлять, что обусловлено потребностями человека, одной из которых является наличие дома и связанного с ним комфортного существования.

Кочевник мобилен: он в любой момент может начать движение, подстраиваясь под сложившиеся обстоятельства. Характеризуя его образ жизни, У. Митчелл справедливо заметил, «в кочевом электронном мире я становлюсь двуногим терминалом, ходячим IP-адресом, а может, еще и беспроводным маршрутизатором в импровизированной мобильной сети», где необходимыми оказываются только паспорт, кредитка и переносное электронное оборудование [19]. 
Зоной пребывания кочевника оказывается виртуальность, не рождающая оседлости и корней в бытии в виду ее возможного и ризомного характера. Кочевник живет по закону: «Я - часть сетей, а сеть - часть меня... Я на связи - значит я существую» [19]. Медийные технологии, характеризующиеся высокоскоростной «прозрачностью передачи информации» «становятся основой для эмоционального восприятия, способного поддержать рефлексивное общественное взаимодействие» [11, с. 241], но при этом рождающие рассеянное состояние сознания. Обладая подобным сознанием человек не способен сосредотачиваться на чем-то одном, постоянно переключая свое внимание и не вникая в содержание происходящего. Подчеркнем, в современности кочевничество обладает всеохватывающим характером, проявляясь в мышлении и действиях.

Электронный кочевник соткан из противоречий: с одной стороны, он мобилен, но с другой стороны, - живет «бешено неподвижно», в ситуации, где ничего не происходит. Кочевник существует «в точках, где электронные потоки информации, подвижные субъекты и реальные пространства сходятся самым полезным и приятным образом» [19], но при этом он «вынужден жить в атмосфере риска, где знания и изменения нестабильны» [11, с. 303]. Еще одна проблема двойственности существования электронного кочевника связана с его интеллектуальностью. Кочевник без проблем владеет навыками пользования техническими средствами, имеющими характер привычки, что не только оглупляет его, но и делает беспомощным при технических сбоях. Более того, с помощью техники возможно быстрое нахождение любой информации, но кочевник не вчитывается в ее содержание и не подвергает критическому осмыслению, поэтому информация довольно быстро стирается из памяти. В итоге личность не становится «исходным пунктом абсолютной достоверности»: она не способна жить по принципу «я мыслю, я существую, я могу», теряя возможность «по-человечески действовать, за что-то отвечать и что-то знать» [12, с. 109-110].

Взаимодействие с другими людьми у кочевника приобретает отчужденно-анонимный характер. С одной стороны, коммуникация в виртуальном пространстве не имеет границ, но с другой стороны, она оказывается отчужденной, а нередко симулятивной 
и мифизированной. Более того, по желанию самого кочевника он может произвольно включаться в контакт и выходит из него, являя тем самым мерцание жизни: кочевник то присоединяется, то изолируется от контактов в виртуальном мире. Аналогичным образом он проявляет себя и в действительности, то появляясь в ней, то погружаясь в виртуальность, что делает его неуловимым, особенно если он меняет свои электронные адреса и аватарки.

Одной из реальных угроз в бытии кочевника являются вирусы, спам и хакерские атаки. Так, «кибератака может исходить из любой части земного шара, от любого государства, группы или лица», а «идентифицировать или выследить всех потенциальных киберпротивников практически невозможно не только для частных компаний, но и для правительств» [19].

В целом, электронный кочевник - это человек-пользователь, который должен иметь доступ к сети. В его жизни оказываются размытыми границы между действительным и искусственным, реальным и виртуальным. В большей степени, электронный кочевник - личность химеричная, сочетающая в себе несочетаемое: естественное и искусственное. В его виртуальном пространстве можно появиться и исчезнуть, спрятаться за аватарами и нарративами, позиционируя не только реальное, но и мифизированное, симулятивное. Вследствие этого кочевник расщепляет собственное Я на множество Я (по У. Митчеллу, Я++), что рождает проблемы в социокультурном пространстве.

Подобные изменения в матрице личности неизбежно отражаются на протекании экономических процессов; данные изменения важно учитывать при проведении и осмыслении результатов технологической модернизации российской экономики.

В настоящее время не существует типовых рекомендаций и моделей диагностики результативности организационных и технологических изменений, а также результативности проектов внедрения технологических новшеств как среди отечественных, так и среди зарубежных ученых и практиков.

Имеют место отдельные разработки в сфере грузовых автомобильных перевозок [2], которые позволили авторам уточнить результативность организационных изменений в зависимости от стадий жизненного цикла организаций автомобильных грузовых перевозок. 
Вузы в настоящее время также вынуждены активно включаться в процессы внедрения и использования информационных систем, в условиях динамического развития культурно-образовательного пространства, характеризующегося неопределенностью и неоднозначностью бизнес-процессов, связанных с передачей и воспроизводством знаний [6]. Что помимо прочего вызывает повышение спроса на информационные системы поддержки принятия управленческих решений. Современным менеджерам важно понимание сложных взаимоотношений между применением инструментов управленческого учета в предпринимательской деятельности, корпоративных особенностей и корпоративного управления, считает Quang Linh Huynh [24].

Предприятия и организации здравоохранения также активно переходят на использование информационных технологий [21], о чем упоминают многие авторы [10]. Важно, что затраты на технологические инновации, которые выражается в денежных единицах, фактические затраты, связанные с осуществлением различных видов инновационной деятельности, осуществляемых на региональном уровне - считаются одним из важнейших показателей инновационного потенциала региона [23].

Организации финансового сектора экономики в настоящее время являются драйверами внедрения информационных систем в производственные и инфраструктурные процессы в связи с базовыми потребностями их бизнеса в результате развития электронной коммерции и соответственно, кибер-мошенничества ${ }^{1}$. На российском рынке автоматизированных банковских систем предложения формируют преимущественно отечественные производители: R-StyleSoftlab, Диасофт, ЦФТ, Инверсия [16]. В частности, это связано с тем, что российские пользователи не привыкли платить большие деньги за зарубежные программы. В то же время, в процессе развития российской банковской системы

${ }^{1}$ В России ужесточили ответственность за кибермошенничество, поправки были внесены в Уголовный кодекс Российской Федерации (Федеральный закон от 8 июня 2015 г. N 153-Ф3 «О внесении изменений в статью 187 Уголовного кодекса Российской Федерации»). 
было потрачено достаточно много сил и средств на автоматизацию процессов, в результате чего сегодня российские разработчики выпускают вполне конкурентоспособные автоматизированные банковские системы.

Взяв за основу идеи Дж. Томпсона [22] и М. Портера [20], Ч. Стабелл и О. Фьельдстад делают вывод о том, что с точки зрения организации производства, построение производственных процессов переходит в современной экономике от линейного и последовательного характера к сетевым формам организации, в основе которых лежат системы однотипных процессов взаимодействия потребителей друг с другом [9]. Для реализации таких форм взаимодействия применяются различные средства автоматизации - в том числе - информационные системы (класса CRM, ERP и др.), а также сетевые информационные ресурсы (сайты в сети Интернет, социальных сетях и т.п.)

Ч. Стабелл и О. Фьельдстад представили три базовых процесса создания ценности [26]:

1. цепочка создания ценности;

2. мастерская создания ценности;

3. сеть создания ценности.

Цепочка создания ценности имеет строго последовательный производственный процесс создания конкретного продукта. Устойчивое преимущество цепочки создания ценности достигается за счет постоянного контроля этих параметров, снижения всех видов издержек, совершенствования бизнес-процессов и повышения производственного качества. Важный критерий цепочки - это эффективность [9].

Мастерская создания ценности направлена на решение проблем потребителей, что и обуславливает не линейность производственного процесса, а представление его как набора определенных проектов. Важным становится степень уникальности решаемых проблем, определяющая и размер рынка, и размер создаваемой ценности, и уровень квалификации персонала.

Сеть создания ценности рассматривается как процесс создания инфраструктуры, объединяющей потребителей, желающих быть 
временно взаимозависимыми, оставаясь в целом независимыми и разделенными в пространстве и времени. В этом случае выделяются процессы создания и поддержания инфраструктуры, и множественные однотипные процессы взаимодействия потребителей друг с другом. Ключевая характеристика сети создания ценности максимальная эффективность эксплуатации имеющейся инфраструктуры и повышение ценности клиентской базы, как для самих участников, так и для третьих сторон [9].

В результате анализа могут быть выделены следующие поведенческие факторы, которые необходимо учитывать при планировании мер по внедрению и последующему использованию технологических новшеств экономическими агентами российской экономики (таблица 1).

Таблийа 1.

Поведенческие факторы, которые необходимо учитывать при планировании и внедрении технологических новшеств

\begin{tabular}{|c|c|c|c|}
\hline № & Название & Описание & Риски \\
\hline 1 & $\begin{array}{l}\text { Переход от ли- } \\
\text { нейных к се- } \\
\text { тевым формам } \\
\text { организации }\end{array}$ & $\begin{array}{l}\text { Данные процессы уже активно } \\
\text { идут, что соответствует резуль- } \\
\text { татам исследований многих } \\
\text { ученых в области экономики и } \\
\text { других наук }\end{array}$ & $\begin{array}{l}\text { Игнорирование данного } \\
\text { фактора при планиро- } \\
\text { вании изменений не } \\
\text { позволит организации } \\
\text { быть достаточно гиб- } \\
\text { кой, чтобы адаптиро- } \\
\text { ваться к быстро изменя- } \\
\text { ющейся внешней среде }\end{array}$ \\
\hline 2 & $\begin{array}{l}\text { Сохранение } \\
\text { форм личной } \\
\text { зависимости и } \\
\text { патернализма } \\
\text { в контрактных } \\
\text { отношениях } \\
\text { между экономи- } \\
\text { ческими субъ- } \\
\text { ектами }\end{array}$ & $\begin{array}{l}\text { Экономика развивается неравно- } \\
\text { мерно, определенные сферы эко- } \\
\text { номических отношений имеют } \\
\text { более благоприятную картину } \\
\text { по распределению прав соб- } \\
\text { ственности, какие-то сохраняют } \\
\text { большую часть пережитков } \\
\text { командно-административной } \\
\text { системы хозяйствования; к тому } \\
\text { же менталитет населения меня- } \\
\text { ется крайне медленно, особенно } \\
\text { в менее развитых субъектах Рос- } \\
\text { сийской Федерации }\end{array}$ & $\begin{array}{l}\text { Игнорирование данного } \\
\text { фактора при планирова- } \\
\text { нии изменений вызовет } \\
\text { стойкое сопротивление } \\
\text { изменениям со стороны } \\
\text { исполнителей - конеч- } \\
\text { ных пользователей, что } \\
\text { усиливает важность } \\
\text { предварительной под- } \\
\text { готовки бизнес-процес- } \\
\text { сов перед внедрением } \\
\text { технологических нов- } \\
\text { шеств }\end{array}$ \\
\hline
\end{tabular}


Окончание табл. 1.

\begin{tabular}{|c|c|c|c|}
\hline 3 & $\begin{array}{l}\text { Тенденция де- } \\
\text { индустри-али- } \\
\text { зации }\end{array}$ & $\begin{array}{l}\text { Ситуация, когда занятие про- } \\
\text { изводственной деятельности } \\
\text { является не привлекательной } \\
\text { для основной массы экономиче- } \\
\text { ских агентов, а складывающаяся } \\
\text { эконмическая ситуация влечет } \\
\text { тенденции по упрощению про- } \\
\text { изводимого товара, деквалифи- } \\
\text { кацию труда, отчуждение и т.п. }\end{array}$ & $\begin{array}{l}\text { Игнорирование дан- } \\
\text { ного фактора при пла- } \\
\text { нировании изменений } \\
\text { влечет за собой новые } \\
\text { формы сублимации, } \\
\text { связанные с низким } \\
\text { уровнем личной от- } \\
\text { ветственности, халат- } \\
\text { ностью, безудержным } \\
\text { ростом потребления и } \\
\text { развлечений }\end{array}$ \\
\hline 4 & $\begin{array}{l}\text { Оппортунисти- } \\
\text { ческое поведе- } \\
\text { ние }\end{array}$ & $\begin{array}{l}\text { Сопротивление изменениям, } \\
\text { возможность лавирования в } \\
\text { ситуациях, сопровождающаяся } \\
\text { сменой альтернатив и стратегий, } \\
\text { что подрывает стабильность раз- } \\
\text { вития, рождает множество ми- } \\
\text { физаций и симулякров, в хитро- } \\
\text { сплетении которых оказывается } \\
\text { невозможным разобраться }\end{array}$ & $\begin{array}{l}\text { Игнорирование дан- } \\
\text { ного фактора влечет } \\
\text { за собой повышение } \\
\text { транзакционных и } \\
\text { прямых издержек на } \\
\text { реализацию проектов } \\
\text { модернизации }\end{array}$ \\
\hline 5 & $\begin{array}{l}\text { Высокая мо- } \\
\text { бильность } \\
\text { экономических } \\
\text { объектов и } \\
\text { субъектов }\end{array}$ & $\begin{array}{l}\text { Приводит к быстрому реагиро- } \\
\text { ванию на ситуацию и изменения } \\
\text { рыночных условия и макроэко- } \\
\text { номической среды }\end{array}$ & $\begin{array}{l}\text { Игнорирование данно- } \\
\text { го фактора оборачива- } \\
\text { ется невозможностью } \\
\text { прогнозировать по- } \\
\text { следствия как позитив- } \\
\text { ные, так и негативные }\end{array}$ \\
\hline
\end{tabular}

Внедрение информационных систем в российской экономике сталкивается с рядом проблем, являющихся следствием существующей системы производственных отношений. Это неизбежно, поскольку российская экономика, как и любая другая национальная экономика, обладает своими особенностями, которые сложились в результате сочетания определенных социально-исторических моментов.

Так, например, сторонники индустриализации утверждают, что текущая неустойчивость национальной экономики и чрезмерная зависимость от природной ренты стала результатом активно проводимой политики деиндустриализации [5]. Ее проявлением, по мнению С.Д. Бодрунова, является так называемый «эффект четырех де», приводящий к технологическому отставанию страны и охватывающий ряд негативных последствий: «дезорганизации процесса про- 
изводства, деградации применяемых технологий, деквалификации труда в производстве и декомпилирования (упрощения) продукта производства» [4].

Второй, не менее распространенный подход - институциональный. По мнению его сторонников, недостаточная развитость институциональной среды и незавершенность институциональных преобразований наблюдается в России уже на протяжении трех веков: «Россия, - по словам А.А. Аузана, - как бы зависла в пространстве, когда традиционное общество уже не восстановимо, ... а модернизированное общество, которое связано с институтами, мы никак не можем создать» [3]. Всё это оказывает влияние на протекание модернизационных процессов в отечественной экономике, в том числе, на модернизацию технологическую, которая подразумевает зачастую более широкое использование информационных технологий и систем.

Кроме того, имеет значение тот факт, что особенностью отношений собственности российской экономики считается существование форм личной зависимости и патернализма [17]. Это влечет за собой возникновения организационных сложностей при внедрении информационных систем и требует по идее более тщательного планирования организационных изменений, сопутствующих использованию технологических новшеств.

\section{Заключение}

В целом, в работе на основе анализа современных изменений поведенческой матрицы личности (постепенный всеобщий переход к «электронному кочевничеству») был проведен анализ факторов, оказывающих влияние на проведение технологической модернизации в экономике России. В результате могут быть выделены следующие факторы, которые необходимо учитывать при планировании мер по внедрению и последующему использованию технологических новшеств самыми разнообразными экономическими агентами российской экономики (вузами, организациями финансового и реального секторов экономики, государственными организациями и ведомствами):

- переход от линейных к сетевым формам организации;

- coхранение форм личной зависимости и патернализма в контрактных отношениях между экономическими субъектами; 
- тенденция деиндустриализации;

- оппортунистическое поведение;

- высокая мобильность экономических объектов и субъектов.

Это создает базу для дальнейшего изучения особенностей внедрения технологических новшеств российскими вузами, государственными учреждениями и организациями, компаниями реального и финансового сектора экономики.

\section{Список литературы}

1. Алексеева И.Ю., Аршинов В.И., Чеклецов В.В. «Технолюди» против «Постлюдей»: НБИКС-революция и будущее человека // Вопросы философии. 2013. № 3. С. 12-21.

2. Антипов Д.С. Методика диагностики результативности организационных изменения в автотранспортных организациях сферы грузовых перевозок // Наука красноярья. 2017. Том 6, №1. С. 64-78.

3. Аузан А.А. Мы приближаемся к моменту истины нашей цивилизации // Свободный мир. 2011. Режим доступа: http://www.liberty.ru/Themes/ Aleksandr-Auzan-My-priblizhaemsya-k-momentu-istiny-nashej-civilizacii

4. Бодрунов С.Д. Грядущее. Новое индустриальное общество: перезагрузка. СПб.: ИНИР им. С.Ю. Витте, 2016. 328 с.

5. Гловин Д.С. Препятствия осуществления экономической модернизации в сфере производственных отношений современной России // Проблемы современной экономики. 2017. №1(61). С. 13-15.

6. Горнева Е.А., Морозова Е.И., Погонышева Д.А. Информационные системы поддержки принятия решений в управлении интеллектуальным потенциалом вуза // Наука красноярья. 2016. №4(37). С. 139-154.

7. Григорьева Н.С., Балашова Е.Я. Импортозамещение в сфере информационных технологий // В сборнике: Международный симпозиум по управлению, экономике и финансам, сборник научных статей. Институт управления, экономики и финансов КФУ. 2016. С. 453-455.

8. Григорьева О.В., Яковлева Е.Л., Григорьева Н.С., Кундакчян Р.М., Ванюхина Н.В., Манушин Д.В., Шакирьянова А.И. Экономическая психология: научные очерки / Под ред. А.В. Тимирясовой // Казань, 2016. Изд-во «Познание». 200 с.

9. Демьянова О.В., Якупов А.Н., Билданов Р.Р. Методологические основы процессного подхода в практике промышленных пред- 
приятий // Проблемы современной экономики. 2017. №1(61). С. $79-82$.

10.Киселев А.С. Влияние высокотехнологичной медицины на развитие человеческого капитала и рост экономики // Проблемы современной экономики. 2017. 31(61). С. 174-177.

11. Маккуайр С. Медийный город: медиа, архитектура и городское пространство. М.: Strelka Press, 2014. 392 c.

12. Мамардашвили М.К. Сознание и цивилизация // Мамардашвили М.К. Как я понимаю философию. М.: Прогресс, 1990. С. 107-121.

13.Независимый портал ERP_online. URL: http://www.erp-online.ru/ phparticles/show_news_one.php?n_id=211

14. Чаадаев П.Я. Философические письма. М.: Римис, 2011. 272 с.

15. Яковлева Е.Л. Электронный кочевник как новая форма идентификации личности // Философия и культура. 2015. № 11. С. 1655-1664.

16. Ясенев В.Н., Ясенев О.В. Информационные системы в экономике: конспект лекций по направлению «Экономика», «Менеджмент», «Таможенное дело». Москва, 2016. Режим доступа: http://yasenev. net/wp-content/uploads/2016/11/konspekt-lektsij.pdf

17. Ясин Е., Снеговая М. Институциональные проблемы России в мировом контексте // Вопросы экономики. 2010. № 1. С. 114-128.

18. McLuhan M. Understanding Media: The Extensions of Man. N.Y.: McGraw Hill, 1964.

19. Mitchell W.J. Me++: The Cyborg Self and the Networked City. Cambridge, Mass. London: MIT, 2004.

20. Porter M.E. Competitive Advantage. N.Y.: Free Press, 1985.

21. PRISMA «Pan-European changes and trends in eHealth services delivery». Режим доступа: http:/www.prisma-eu.net/deliverables/trendhealth

22. Thompson J.D. Organizations in action; social science bases of administrative theory. N.Y.: McGraw-Hill, 1967.

23. Tsepelev O., Kakaulina M. Modeling the Impact of Taxes on Economic Growth with Regional Resource Potential // American Journal of Applied Sciences 2015, 12 (5): 345.354.

24. Quang Linh Huynh. Corporate Governance on the Corporate Characteristics - Managerial Accounting link // American Journal of Applied Sciences 2017. Режим доступа: http://thescipub.com/PDF/ofsp.11231.pdf 
25. Wan Azlin Zurita Wan Ahmad and Muriati Mukhtar. A Social Content Management Model based on the DART Model // American Journal of Applied Sciences 2017, 14 (1): 25.33.

26. Stabell C.B., Fjelstad O.D. Configuring value for competitive advantage: on chains, shops and networks // Strategic Management Journal. 1998. Vol. 19, pp. 413-437.

\section{References}

1. Alekseeva I.Yu., Arshinov V.I., Chekletsov V.V. «Tekhnolyudi» protiv «Postlyudey»: NBIKS-revolyutsiya i budushchee cheloveka [“Technology" against "Postlude": NBICS the revolution and the future of man]. Voprosy filosofii. 2013. № 3, pp. 12-21.

2. Antipov D.S. Metodika diagnostiki rezul'tativnosti organizatsionnykh izmeneniya $\mathrm{v}$ avtotransportnykh organizatsiyakh sfery gruzovykh perevozok [The technique of diagnostics of the effectiveness of institutional changes in transportation organizations freight transportation]. Nauka krasnoyar'ya. 2017. V. 6, №1, pp. 64-78.

3. Auzan A.A. My priblizhaemsya k momentu istiny nashey tsivilizatsii [We are approaching to the moment of truth of our civilization]. Svobodnyy mir. 2011. http://www.liberty.ru/Themes/Aleksandr-Auzan-My-priblizhaemsya-k-momentu-istiny-nashej-civilizacii

4. Bodrunov S.D. Gryadushchee. Novoe industrial'noe obshchestvo: perezagruzka [Future. The new industrial society: reloaded]. SPb.: INIR im. S.Yu. Vitte, 2016. 328 p.

5. Glovin D.S. Prepyatstviya osushchestvleniya ekonomicheskoy modernizatsii v sfere proizvodstvennykh otnosheniy sovremennoy Rossii [Barriers to the implementation of economic modernization in the field of industrial relations in modern Russia]. Problemy sovremennoy ekonomiki. 2017. №1(61), pp. 13-15.

6. Gorneva E.A., Morozova E.I., Pogonysheva D.A. Informatsionnye sistemy podderzhki prinyatiya resheniy v upravlenii intellektual'nym potentsialom vuza [Information system for decision support in the management of intellectual potential of the University]. Nauka krasnoyar'ya. 2016. №4(37), pp. 139-154.

7. Grigor'yeva N.S., Balashova E.Ya. Importozameshchenie v sfere informatsionnykh tekhnologiy [Import substitution in the information 
technology]. Mezhdunarodnyy simpozium po upravleniyu, ekonomike i finansam, sbornik nauchnykh statey. Institut upravleniya, ekonomiki $i$ finansov KFU. 2016, pp. 453-455.

8. Grigoreva O.V., Yakovleva E.L., Grigoreva N.S., Kundakchyan R.M., Vanyukhina N.V., Manushin D.V., Shakir'yanova A.I. Ekonomicheskaya psikhologiya: nauchnye ocherki [Economic psychology: scientific essays]. A.V. Timiryasova (ed.). Kazan', 2016. Izd-vo «Poznanie». 200 p.

9. Dem'yanova O.V., Yakupov A.N., Bildanov R.R. Metodologicheskie osnovy protsessnogo podkhoda $\mathrm{V}$ praktike promyshlennykh predpriyatiy [Methodological basis of the process approach in the practice of industrial enterprises]. Problemy sovremennoy ekonomiki. 2017. №1(61), pp. 79-82.

10. Kiselev A.S. Vliyanie vysokotekhnologichnoy meditsiny na razvitie chelovecheskogo kapitala i rost ekonomiki [The impact of high-tech medicine on the development of human capital and economic growth]. Problemy sovremennoy ekonomiki. 2017. 31(61), pp. 174-177.

11. Makkuayr S. Mediynyy gorod: media, arkhitektura i gorodskoe prostranstvo [The media city: media, architecture and urban space]. M.: Strelka Press, 2014. 392 p.

12. Mamardashvili M.K. Soznanie i tsivilizatsiya [Consciousness and civilization]. M.: Progress, 1990, pp. 107-121;

13.ERP_online. http://www.erp-online.ru/phparticles/show_news_one.ph$\mathrm{p} ? \mathrm{n} \_\mathrm{id}=211$

14. Chaadaev P.Ya. Filosoficheskie pis'ma [Philosophical letter]. M.: Rimis, 2011. $272 \mathrm{p}$.

15. Yakovleva E.L. Elektronnyy kochevnik kak novaya forma identifikatsii lichnosti [E-nomad as a new form of identification]. Filosofiya i kul'tura. 2015. № 11, pp. 1655-1664.

16. Yasenev V.N., Yasenev O.V. Informatsionnye sistemy v ekonomike: konspekt lektsiy po napravleniyu «Ekonomika», «Menedzhment», "Tamozhennoe delo» [Information systems in the economy: lectures on «Economics», «Management», «Customs business»]. M., 2016. http://yasenev.net/ wp-content/uploads/2016/11/konspekt-lektsij.pdf

17. Yasin E., Snegovaya M. Institutsional'nye problemy Rossii v mirovom kontekste [Institutional problems of Russia in the global context]. Voprosy ekonomiki. 2010. № 1, pp. 114-128. 
18. McLuhan M. Understanding Media: The Extensions of Man. N.Y.: McGraw Hill, 1964.

19. Mitchell W.J. Me++: The Cyborg Self and the Networked City. Cambridge, Mass. London: MIT, 2004.

20.Porter M.E. Competitive Advantage. N.Y.: Free Press, 1985.

21.PRISMA «Pan-European changes and trends in eHealth services delivery».: http://www.prisma-eu.net/deliverables/trendhealth

22. Thompson J.D. Organizations in action; social science bases of administrative theory. N.Y.: McGraw-Hill, 1967.

23. Tsepelev O., Kakaulina M. Modeling the Impact of Taxes on Economic Growth with Regional Resource Potential. American Journal of Applied Sciences 2015, 12 (5): 345.354

24. Quang Linh Huynh. Corporate Governance on the Corporate Characteristics- Managerial Accounting link. American Journal of Applied Sciences 2017. http://thescipub.com/PDF/ofsp.11231.pdf

25. Wan Azlin Zurita Wan Ahmad and Muriati Mukhtar. A Social Content Management Model based on the DART Model. American Journal of Applied Sciences 2017, 14 (1): 25.33.

26. Stabell C.B., Fjelstad O.D. Configuring value for competitive advantage: on chains, shops and networks. Strategic Management Journal. 1998. Vol. 19, pp. 413-437.

\section{ДАННЫЕ ОБ АВТОРАХ}

Яковлева Елена Людвиговна, заведующий кафедрой «Философии и социально-политических дисциплин», доктор философских наук

Казанский инновачионный университет им. В.Г.Тимирясова ул. Московская, 42, г. Казань, Республика Татарстан, 420111, Российская Федерация mifoigra@yandex.ru

Селиверстова Наталья Сергеевна, ассистент кафедры «Экономическая теория», кандидат экономических наук Казанский (Приволжский) федеральный университет ул. Бутлерова, 4, г. Казань, Республика Татарстан, 445067, 
Российская Федерация

nat-grig17@yandex.ru

Григорьева Ольга Витальевна, заведующий кафедрой «Психологии развития и психофизиологии», кандидат биологических наук Казанский инновационный университет им. В.Г. Тимирясова ул. Московская, 42, г. Казань, Республика Татарстан, 420111, Российская Федерации g-pf@yandex.ru

\section{DATA ABOUT THE AUTHORS}

Iakovleva Elena Ludvigovna, Head of the Chair Philosophy and Social and Political Sciences, Doctor of Philosophy Sciences, Professor Kazan Innovation University named after V.G. Timiryasova (Kazan) 42, Moskovskaya Str., Kazan, Tatarstan Republic, 420111, Russian Federation mifoigra@yandex.ru

Seliverstova Nataliya Sergeevna, Assistant «Economic theory», Candidate of Economic Sciences Kazan Federal University 18, Kremlevskaya Str., Kazan, Tatarstan Republic, 420115, Russian Federation nat-grig17@yandex.ru ORCID: 0000-0002-9910-6192 ResearcherID: F-9231-2015 Scopus Author ID: 56373312900

Grigoryeva Olga Vitalievna, Head of the Department «Developmental Psychology and Psychophysiology», Candidate of Biological Sciences

Kazan Innovation University named after V.G. Timiryasova (Kazan) 42, Moskovskaya Str., Kazan, Tatarstan Republic, 420111, Russian Federation g-pf@yandex.ru Scopus Author ID: 56662926400 